\title{
Determinants of Bus Dwell Time
}

\author{
Kenneth J. Dueker, Thomas J. Kimpel, James G. Strathman \\ Portland State University \\ Steve Callas, TriMet
}

\begin{abstract}
Bus dwell time data collection typically involves labor-intensive ride checks. This paper reports an analysis of bus dwell times that use archived automatic vehicle location (AVL)/automatic passenger counter (APC) data reported at the level of individual bus stops. The archived data provide a large number of observations that serve to better understand the determinants of dwells, including analysis of rare events, such as lift operations. The analysis of bus dwell times at bus stops is applicable to TriMet, the transit provider for the Portland metropolitan area, and transit agencies in general. The determinants of dwell time include passenger activity, lift operations, and other effects, such as low floor bus, time of day, and route type.

\section{Introduction}

Bus dwell time data collection typically involves labor-intensive ride checks. This paper reports an analysis of bus dwell times that use archived automatic vehicle location (AVL)/automatic passenger counter (APC) data reported the level of individual bus stops. The archived AVL/APC data provides a rich set of dwell time observations to better understand the determinants of dwells. In addition, the large quantity of data allows analysis of rare events, such as lift operations. The analysis of bus dwell times at bus stops was originally used to estimate delay associated with bus lift use operations for passengers with disabilities in the Tri-County Metropolitan Transportation District of Oregon (TriMet), the transit provider for
\end{abstract}


the Portland metropolitan area (Dueker, et al. 2001). In addition, the analysis yielded useful information about dwell times that has applicability to transit agencies in general.

The estimated models provide a system-wide baseline. Stop-level, route-level, operator-specific, and passenger boarding-level analyses can follow. This paper includes examples of applying the model results to simulate dwell times for different times of day, route types, and various levels of passenger boardings and alightings. The effects of fare payment method and bicycle rack usage on dwell times was unable to be incorporated, but suggest how future research could extend the model.

\section{Prior Work}

Literature on bus dwell times is sparse, due to the cost and time required for manual data collection. Consequently, most prior analyses tend to be route-specific, focus on analyzing various issues causing bus delay, and are based on small samples. Previous studies on dwell time have used ordinary least squares (OLS) regression to relate dwell time to boardings and alightings, with separate equations estimated for different operating characteristics likely to affect dwell time. Kraft and Bergen (1974) found that passenger service time requirements for AM and $P M$ peaks are similar, midday requirements are greater than those in peak periods, boarding times exceed alighting times, and rear door and front door alighting times are the same. They also found that dwell time is equal to 2 seconds plus 4.5 seconds per boarding passenger for cash and change fare structures, and 1.5 seconds plus 1.9 seconds for exact fare.

Levinson's (1983) landmark study of transit travel time performance reported that dwell time is equal to 5 seconds plus 2.75 seconds per boarding or alighting passenger. Guenthner and Sinha (1983) found a 10-20 second penalty for each stop plus a 3-5 second penalty for each passenger boarding or alighting. However, dwell time models based on small samples have low explanatory power, even when controlling for factors such as lift activity, fare structure, and number of doors. Guenthner and Hamet (1988) looked at the relationship between dwell time and fare structure, controlling for the amount of passenger activity. Lin and Wilson (1992) reviewed prior work and formulated a model of dwells as a function of boardings, alightings, and interference with standees, which was then applied to light rail transit dwells. Bertini and El-Geneidy (2004) modeled dwell time for a single inbound radial route in the morning peak period in their analysis of trip 
level running time. They incorporated the results of the dwell time analysis directly into the trip time model by estimating parameters for number of dwells and number of boarding and alighting passengers.

\section{Data Issues}

Dwell time is defined as "the time in seconds that a transit vehicle is stopped for the purpose of serving passengers. It includes the total passenger service time plus the time needed to open and close doors" (HCM 1985).

In the past, dwell time data collection consisted of placing observers at highly utilized bus stops to measure passenger service times, and by ride checks or onboard observers for dwells at bus stops along routes. The ride check procedure as prescribed in the Transit Capacity and Quality of Service Manual consists of the following steps to collect field data for estimating passenger service times:

1. From a position on the transit vehicle, record the stop number or name at each stop.

2. Record the time that the vehicle comes to a complete stop.

3. Record the time that the doors have fully opened.

4. Count and record the number of passengers alighting and the number of passengers boarding. (The data collection form calls for front and rear door specific counts).

5. Record the time that the major passenger flows end.

6. When passenger flows stop, count the number of passengers remaining on board. (Note: If the seating capacity of the transit vehicle is known, the number of passengers on board may be estimated by counting the number of vacant seats or the number of standees).

7. Record time when doors have fully closed.

8. Record time when vehicle starts to move. (Note: Waits at timepoints or at signalized intersections where dwell is extended for cycle should be noted but not included in the dwell time. Delays at bus stops when a driver is responding to a passenger information request are everyday events and should be included in the calculation of dwell time. Time lost dealing with fare disputes, lost property or other events should not be included.)

9. Note any special circumstances. In particular, any wheelchair movement times should be noted. Whether this is included in the mean dwell time 
depends on the system. Dwell times due to infrequent wheelchair movements are often not built into the schedule but rely on the recovery time allowance at the end of each run. The observer must use judgment in certain cases. At nearside stops before signalized intersections the driver may wait with doors open as a courtesy to any late-arriving passengers. The doors will be closed prior to a green light. This additional waiting time should not be counted as dwell time but as intersection delay time. (TCRP 1999)

Automating the collection of dwell time data through the employment of AVL and APC technologies compromises the procedures outlined above. The dwell time is measured as specified, but the time the bus stops and starts is not recorded, nor is the starting and stopping of passenger flows. Our analysis deleted dwells of over 180 seconds ( 3 minutes). This censoring was done to purge the analysis of dwells that are abnormal. Also, TriMet's Automated Passenger Counters (APC) record total boardings and alightings rather than door-specific counts. Finally, there is no guarantee that operators will behave similarly in closing the doors while awaiting for traffic to clear or traffic signals to change. These compromises to the conventional measurement of dwell time are offset by the ability to collect data on large numbers of dwells, with any "special circumstances" included in the error term of OLS regression models.

\section{Automating Collection of Dwell Time Data}

Uses of Archived AVL/APC Data to Improve Transit Performance and Management (Furth, et al. forthcoming), identifies the bus stop as the appropriate spatial unit for data aggregation and integration. This integration of scheduled and actual arrival time at the level of the individual stop is crucial for research on bus operations and control strategies. Integrating data at the bus stop level supports real time applications, such as automated stop annunciation and next-stop arrival time information. Importantly, if bus stop data are archived, operations performance and monitoring analysis can also be supported (Furth, et al. forthcoming).

TriMet has automated the collection and recording of bus dwell time and passenger activity at the bus stop level, and archives the data consistent with the TCRP recommendations. TriMet operates 97 bus routes, 38 miles of light rail transit, and 5 miles of streetcar service within the tri-county Portland metropolitan region. TriMet's bus lines carry approximately 200,000 trips per day, serving a total popu- 
lation of 1.3 million persons within an area of 1,530 square kilometers (590 square miles).

TriMet implemented an automated Bus Dispatch System (BDS) in 1997 as a part of an overall operation and monitoring control system upgrade.

The main components of the BDS include:

1. AVL based upon differential global positioning system (GPS) technology, supplemented by dead reckoning sensors

2. Voice and data communication system using radio and cellular digital packet data (CDPD) networks

3. On-board computer and control head displaying schedule adherence information to operators and showing dispatchers detection and reporting of schedule and route adherence

4. APCs on front and rear doors of $70 \%$ of vehicles in the bus fleet

5. Computer-aided dispatch (CAD) center

The BDS reports detail operating information in real time by polling bus location every 90 seconds, which facilitates a variety of control actions by dispatchers and field supervisors. In addition, the BDS collects detailed stop-level data that are downloaded from the bus at the end of each day for post-processing. The archived data provide the agency with a permanent record of bus operations for each bus in the system at every stop on a daily basis. These data include the actual stop time and the scheduled time, dwell time, and the number of boarding and alighting passengers. The BDS also logs time-at-location data for every stop in the system, whether or not the bus stops to serve passengers. This archived data forms a rich resource for planning and operational analysis as well as research.

The GPS-equipped buses calculate their position every second, with spatial accuracy of plus or minus 10 meters or better. Successive positions are weeded and corrected by odometer input. When the bus is within 30 meters of the known location of the next bus stop (which is stored on a data card along with the schedule), an arrival time is recorded. When the bus is no longer within 30 meters of the known bus stop location, a departure time is recorded. If the door opens to serve passengers, a dwell is recorded and the arrival time is overwritten by the time when the door opens. Dwell time (in seconds) is recorded as the total time that the door remains open. 
When passenger activity occurs, the APCs count the number of boardings and alightings. The APCs are installed at both front and rear doors using infrared beams to detect passenger movements. The APCs are only activated if the door opens. The use of a lift for assisting passengers with disabilities is also recorded. TriMet has used on-board cameras to validate APC counts (Kimpel, et al. 2003). The validation procedures could be extended to include dwell time and the timing of passenger flows, and perhaps even fare payment if the video clips are not too choppy.

The archived AVL/APC data have been used in various studies of operations control and service reliability (Strathman et al. 1999; Strathman et al. 2000; Strathman et al. 2001a; Strathman et al. 2001b), for route-level passenger demand modeling (Kimpel 2001), for models of trip and dwell time (Bertini and El-Geneidy 2004), and for evaluating schedule efficiency and operator performance (Strathman, et al. 2002).

\section{Dwell Time Data}

The data are from a two-week time period in September 2001 for all of TriMet's regular service bus routes. For this analysis, dwell time (DWELL) is the duration in seconds the front door is open at a bus stop where passenger activity occurs. The data were purged of observations associated with the beginning and ending points of routes, layover points, and unusually long dwell time (greater than $180 \mathrm{sec}-$ onds). ${ }^{1}$ Observations with vehicle passenger loads (LOAD) of over 70 persons were also excluded, indicating the automatic passenger counter data were suspect. Two weeks of data generated over 350,000 dwell observations. Even though lift operations (LIFT) occur in less than one percent $(0.7 \%)$ of dwells, the number of lift operations is large enough for a robust estimation of separate model $(\mathrm{N}=$ $2,347)$.

Table 1 presents descriptive statistics for variables used in the full-sample dwell time model. The mean dwell time is 12.29 seconds, with a standard deviation of 13.47 seconds. On average, there were 1.22 boardings and 1.28 alightings per dwell. Also, $61 \%$ of the dwells involved low floor buses. Dwells by time of day (TOD) are $15 \%$ in morning peak period (6-9 AM) (TOD1), $41 \%$ in midday (9 AM -3 PM) (TOD2), 17\% in afternoon peak period (3-6 PM) (TOD3), 21\% in evening (6-10 PM) (TOD4), and 7\% in late night and early morning (10 PM- 6 AM) (TOD5). The mix of dwells by route type is $71 \%$ for radial, $4 \%$ feeder, and $25 \%$ cross-town. Also, the average dwell occurs 2.36 minutes behind schedule (ONTIME). 
Table 1. Bus Dwell Time Descriptive Statistics

\begin{tabular}{|lrrrrr|}
\hline Name & Mean & St. Dev. & Var. & Min. & Max. \\
\hline DWEL & 12.29 & 13.47 & 181.42 & 2.00 & 180.00 \\
ONS & 1.22 & 1.99 & 3.94 & 0.00 & 44.00 \\
ONS2 & 5.43 & 25.79 & 664.92 & 0.00 & 1936.00 \\
OFFS & 1.28 & 1.90 & 3.63 & 0.00 & 47.00 \\
OFF52 & 5.26 & 25.22 & 636.04 & 0.00 & 2209.00 \\
ONTIME & 2.36 & 3.56 & 12.70 & 29.66 & 57.50 \\
UIFT & 0.007 & 0.081 & 0.007 & 0 & 1 \\
LOW & 0.61 & 0.49 & 0.24 & 0 & 1 \\
TOD1 & 0.15 & 0.36 & 0.13 & 0 & 1 \\
TOO2 & 0.41 & 0.49 & 0.24 & 0 & 1 \\
TOD3 & 0.17 & 0.37 & 0.14 & 0 & 1 \\
TOD4 & 0.21 & 0.40 & 0.16 & 0 & 1 \\
TODS & 0.07 & 0.25 & 0.06 & 0 & 1 \\
RAD & 0.71 & 0.45 & 0.21 & 0 & 1 \\
FEED & 0.04 & 0.19 & 0.04 & 0 & 1 \\
XTOWN & 0.25 & 0.43 & 0.19 & 0 & 1 \\
FRICTION & 3.19 & 4.41 & 19.46 & 0 & 73 \\
\hline
\end{tabular}

The analysis includes information derived from three separate but related samples: (1) a full sample consisting of all observations; (2) a lift operation-only sub-sample; and (3) a without lift operation only sub-sample.

Table 2 shows the effect of a lift operation on mean dwell time. Mean dwell times for the sub-sample without lift operation average 11.84 seconds, while mean dwell times for the sub-sample with lift operation average 80.70 seconds. The coefficient of variation for dwell time with lift operation is $46.4 \%$, and $100.7 \%$ for without lift operation. An OLS model for the full sample of both lift and no lift operation had a coefficient of 62.07 for a dummy variable for lift operation (LIFT). ${ }^{2}$ A Chow test indicated that a separate model was needed for dwells where lift operations occur. 
Journal of Public Transportation, Vol. 7, No. 1, 2004

Table 2. Bus Dwell Time Means

\begin{tabular}{|lccr|}
\hline Dwell (seconds) & Mean Time & St. Dev. & \multicolumn{1}{c|}{ N } \\
\hline Sub-sample with lift operation & 80.70 & 37.44 & 2,347 \\
Sub-sample without lift operation & 11.84 & 11.92 & 353,552 \\
Both (full sample) & 12.29 & 13.47 & 355,899 \\
\hline
\end{tabular}

\section{Dwell Time Estimation}

Table 3 presents results of the model of the sub-sample without lift operation. Dwell time is explained by boarding passengers (ONS), alighting passengers (OFFS), whether the bus is ahead or behind schedule (ONTIME), if the bus is a low floor bus (LOW), passenger friction (FRICTION), ${ }^{1}$ time of day (TOD), and type of route feeder (FEED) and cross-town (XTOWN) as compared to radial (RAD). The estimation results indicate that each boarding passenger adds 3.48 seconds to the base dwell time of 5.14 seconds (CONST) and each alighting passenger adds 1.70 seconds. Square terms of passenger activity are used to account for diminishing marginal effects of additional boarding and alighting passengers on dwell time. Each additional boarding passenger is estimated to take 0.04 seconds less, while each additional alighting passenger takes 0.03 seconds less. ${ }^{2}$ The negative coefficient of ONTIME indicates that dwell times tend to be less for late buses than for early buses ${ }^{3}$. The CONST value of 5.14 seconds reflects the basic opening and closing door process.

The other variables have small but significant effects. Time-of-day estimates are referenced to the morning peak period (TOD1). Midday dwells (TOD2) are 1.36 seconds longer than morning peak dwells; afternoon peak dwells (TOD3) are 0.92 seconds longer than morning peak dwells; and evening period dwells (TOD4) are 1.25 seconds longer than morning peak dwells, while late evening and early morning period dwells (TOD5) are not significantly different than morning peak dwells. The morning peak period is the most efficient in terms of serving passengers, perhaps due to regular riders and more directional traffic. Regular riders may tend to board using bus passes ${ }^{6}$ and ask fewer questions. More directional traffic would reduce the mix of boardings and alightings at the same stop. 
The type of route also affects dwell times. Feeder routes have 0.15 second longer dwells than radials, the reference route type, and cross-town routes have 0.39 second shorter dwells than buses operating on radial routes.

Table 3. Bus Dwell Time Model: Without Lift Operation

\begin{tabular}{|lrrr|}
\hline Name & Coeff. & Std. Err. & T-Ratio \\
\hline ONS & 3.481 & 0.015 & 231.90 \\
ONS2 & -0.040 & 0.001 & -37.38 \\
OFFS & 1.701 & 0.015 & 113.00 \\
OFFS2 & -0.031 & 0.001 & -29.11 \\
ONTIME & -0.144 & 0.005 & -30.68 \\
LOW & -0.113 & 0.034 & -3.30 \\
FRICTION & 0.069 & 0.005 & 12.92 \\
TOD2 & 1.364 & 0.049 & 27.82 \\
TOD3 & 0.924 & 0.059 & 15.77 \\
TOD4 & 1.248 & 0.055 & 22.51 \\
TOD5 & 0.069 & 0.076 & 0.91 \\
FEED & 0.145 & 0.086 & 1.70 \\
XTOWN & -0.388 & 0.039 & -9.99 \\
CONST. & 5.136 & 0.051 & 99.96 \\
N & 353,552 & & \\
ADJ. R2 & 0.3475 & & \\
\hline
\end{tabular}

\section{Lift Operation Effects}

The estimated effect of a lift operation on dwell time in a full-sample model is 62.07 seconds. This lift operation effect is examined more closely in a separate model of dwell times involving lift operations only.

Table 4 presents the results of the bus dwell time model for the sub-sample of lift operation-only. The mean dwell time for lift operation-only dwells is $80.70 \mathrm{sec}-$ onds, and is explained by the same variables as the overall dwell time model, but they differ and are less significant. For example, a low-floor bus reduces the dwell time for lift operations by nearly 5 seconds. But the large CONST value of 68.86 
seconds indicates that the majority of time is for the lift operation itself. Boarding activity is estimated to extend dwells at a diminishing marginal rate, while alighting passenger activity does not substantially affect dwell time. However, wheelchairs, walkers, and strollers may confound APCs. There are significant effects by time of day, but they are not easily explained. Lift operations during the morning peak (TOD1) take longer than lift operations at other times.

Table 4. Bus Dwell Time Model: With Lift Operation

\begin{tabular}{|lrrr|}
\hline Name & Coeff. & Std. Err. & T-Ratio \\
\hline ONS & 10.206 & 0.488 & 20.91 \\
ONS2 & -0.359 & 0.029 & -12.31 \\
OFFS & 0.513 & 0.396 & 1.30 \\
OFFS2 & -0.022 & 0.017 & -1.33 \\
ONTIME & -0.037 & 0.176 & -0.21 \\
LOW & -4.741 & 1.388 & -3.42 \\
FRICTION & -0.234 & 0.208 & -1.13 \\
TOD2 & -4.141 & 2.554 & -1.62 \\
TOD3 & -6.271 & 2.869 & -2.19 \\
TOD4 & -4.588 & 2.925 & -1.57 \\
TOD5 & -14.447 & 4.542 & -3.18 \\
FEED & 1.036 & 3.354 & 0.31 \\
XTOWN & -1.675 & 1.519 & -1.10 \\
CONST. & 68.861 & 2.706 & 25.45 \\
\hline N & 2,347 & & \\
ADJ. R2 & 0.2848 & & \\
\hline
\end{tabular}

An estimate of delay associated with lift operation can be used to modify arrival time estimates provided to transit users at downstream stops. However, we have three choices of delay estimates for lift operation. One is 62.07 seconds, the coefficient on LIFT from the full model. Another is the difference between the mean of all dwell time with lift operations ( 80.70 seconds) and without lift operations ( 11.84 seconds). This difference is 68.86 seconds. The third choice is the effect of a lift operation on running time from an earlier study of route running times (Strathman, et al. 2001a). This third choice provides an estimate of the lift effect as 59.80 seconds. This smaller value indicates that before the end of their trip, operators make up some of the time lost due to lift operations. 
We recommend the middle estimate of 62.07 seconds (the coefficient on the LIFT dummy variable from the full sample estimation) be selected as the delay estimate at the outset of the lift event and that it be updated with the actual dwell time less the mean dwell time without lift operation as the bus departs that stop. In this manner, next stop bus arrival time estimates could be refined when impacted by delays associated with lift operations. This would require a message from the bus to the dispatch center at the onset of the lift operation and another at its conclusion.

\section{Low Floor Bus Effect}

TriMet was also interested in the effect of low floor buses on dwells, particularly dwells with lift operations. The dwell time model for the without lift operation sub-sample yields an estimated effect of a low-floor bus of -0.11 seconds $(-0.93 \%)$ per dwell. A typical TriMet route has 60 bus stops. On an average bus trip, buses actually stop at $60 \%$ of them. Thus, the 0.11 second reduction per dwell for a low floor bus translates into a 3.96 second savings in total running time per trip.

The low floor bus effect is examined in a model of dwell times involving lift operations only. The mean dwell time for stops where the lift is operated is $80.70 \mathrm{sec}$ onds. A low-floor bus reduces dwell time for lift operations by nearly 5 seconds (4.74 or $5.8 \%$ ). The impact of low floor buses on dwell time with lift operation is more substantial.

\section{Simulation}

Models can be used to simulate dwell times. The coefficients are multiplied by assumed values of the variables that represent operating conditions of interest. Table 5 presents simulated dwell times for various operating conditions. Although the simulation produces precise dwell time estimates, the results should be viewed in relative terms, because of large coefficients of variation in dwell time and the explanatory power of the models are low (adjusted R2 values of 0.35 for without lift operation and 0.28 for with lift operation).

The first condition simulated is a radial route in the AM peak period. Five boardings (ONS) are assumed to load at a stop and there are no alightings (OFFS). The bus is operating two minutes late. This simulation yields a dwell time estimate of 21.15 seconds. The second simulation is of a radial route in the PM peak operating with five OFFS and no ONS. It also has 10 standees. The dwell time estimate is 13.99 seconds. In comparing the two estimates, a greater time associated with boardings as compared to alightings is quantified. The third simulation is for a cross-town 
Table 5. Simulation of Bus Dwell Times

\begin{tabular}{|l|c|c|c|c|c|c|r|}
\hline Name & Coeff. & \multicolumn{2}{|c|}{$\begin{array}{c}\text { Radial AM } \\
\text { Inbound }\end{array}$} & \multicolumn{2}{c|}{$\begin{array}{c}\text { Radial PM } \\
\text { Outbound }\end{array}$} & \multicolumn{2}{c|}{$\begin{array}{c}\text { Cross-Town } \\
\text { Midday }\end{array}$} \\
\hline ONS & 3.481 & 5 & 17.41 & & 0.00 & 2 & 6.96 \\
ONS2 & -0.040 & 25 & -0.99 & & 0.00 & 4 & -0.16 \\
OFFS & 1.701 & & 0.00 & 5 & 8.50 & 2 & 3.40 \\
OFFS2 & -0.031 & 0 & 0.00 & 25 & -0.78 & 4 & -0.12 \\
ONTIME & -0.144 & 2 & -0.29 & 5 & -0.72 & 2.5 & -0.36 \\
LOW & -0.113 & 1 & -0.11 & 1 & -0.11 & & 0.00 \\
FRICTION & 0.069 & 0 & 0.00 & 10 & 1.04 & & 0.00 \\
TOD2 & 1.364 & & 0.00 & & 0.00 & 1 & 1.36 \\
TOD3 & 0.924 & & 0.00 & 1 & 0.92 & & 0.00 \\
TOD4 & 1.248 & & 0.00 & & 0.00 & & 0.00 \\
TOD5 & 0.069 & & 0.00 & & 0.00 & & 0.00 \\
FEED & 0.145 & & 0.00 & & 0.00 & & 0.00 \\
CTOWN & 0.145 & & 0.00 & & 0.00 & 1 & 0.15 \\
CONST. & 5.136 & 1 & 5.14 & 1 & 5.14 & 1 & 5.14 \\
\hline DWELL EST. & & & 21.15 & & 13.99 & & 16.37 \\
\hline
\end{tabular}

\begin{tabular}{|l|c|r|r|r|r|r|}
\hline \multirow{2}{*}{ Name } & \multicolumn{2}{|c|}{ Lift Specific Model (w/lift only) } & \multicolumn{2}{c|}{ Full Model (w/lift dummy) } \\
\cline { 2 - 7 } & Coeff. & \multicolumn{2}{c|}{$\begin{array}{c}\text { Midday Feeder } \\
\text { Service }\end{array}$} & \multicolumn{2}{c|}{ Coeff. } & \multicolumn{2}{c|}{$\begin{array}{c}\text { Midday Feeder } \\
\text { Service }\end{array}$} \\
\hline ONS & 10.206 & 2 & 20.41 & 3.551 & 2 & 7.10 \\
ONS2 & -0.359 & 4 & -1.43 & -0.042 & 4 & -0.17 \\
OFFS & 0.513 & 1 & 0.51 & 1.703 & 1 & 1.70 \\
OFFS2 & -0.022 & 1 & -0.02 & -0.033 & 1 & -0.03 \\
ONTIME & -0.037 & -1 & 0.04 & -0.145 & -1 & 0.14 \\
LOW & -4.741 & & 0.00 & -0.143 & & 62.07 \\
LIFT &..- &.- &.- & 62.07 & 1 & 0.00 \\
FRICTION & -0.234 & & 0.00 & 0.067 & & 0.00 \\
TOD2 & -4.141 & 1 & -4.14 & 1.352 & 1 & 1.35 \\
TOD3 & -6.271 & & 0.00 & 0.902 & & 0.00 \\
TOD4 & -4.588 & & 0.00 & 1.231 & & 0.00 \\
TOD5 & -14.447 & & 0.00 & -0.013 & & 0.00 \\
FEED & 1.036 & 1 & 1.04 & 0.148 & 1 & 0.15 \\
CTOWN & -1.675 & & 0.00 & -0.390 & & 0.00 \\
CONST. & 68.861 & 1 & 68.86 & 5.117 & 1 & 5.12 \\
\hline DWELL EST. & & & 85.26 & & & 77.43 \\
\hline
\end{tabular}


route in the midday at a stop with two ONS and two OFFS and running 2.5 minutes late. This produces an estimated dwell time of 16.36 seconds.

Table 5 also contains two simulations of a lift operation with two ONS and two OFFS on a feeder line in the midday period with a bus that is running one minute early. This condition is estimated using the lift specific model (dwell estimate of 85.26 seconds) and using coefficients from the full-sample model with a lift dummy variable ( 77.43 seconds). The difference in estimates is less than the standard deviations of either sample.

For a better understanding of boarding and alighting passenger activity, two additional sub-samples were drawn. Both are for radial routes with no lift operation. One was $A M$ peak period dwells with boardings but no alightings, and the other was PM peak period dwells with alightings but no boardings. This allows the estimation of parameters for boardings and alightings that are not confounded by a mixture of boardings and alightings. Table 6 is the dwell time model for boardings only and Table 7 the model for alightings only. The parameter for boardings is 3.83 seconds per boarding passenger and the parameter for alightings is 1.57 seconds per alighting passenger. Again, both parameters have a significant square term that indicates a declining rate for each additional passenger. Simulations for 1, 2, 5, 10, and 15 boarding passengers are contained in Table 8, and simulations for alighting passengers are contained in Table 9. Both simulations assumed an average lateness (ONTIME) value of 1.56 minutes for the boarding passenger sub-sample and 4.46 minutes for the alighting passenger sub-sample. Both simulations also assumed a low floor bus and a bus load of less than 85 percent of capacity. The simulations calculate dwell time in seconds for various boarding and alighting passengers. For instance, dwell time for five boarding passengers is estimated to be 21.01 seconds (from Table 8 ) and is estimated to be 12.75 seconds for five alighting passengers (from Table 9). These two simulations illustrate the benefit of working with large amounts of data that is made possible by automated data collection. We were able to select route type, time of day, and dwells with boardings or alightings, but not both.

Comparison of the simulation of five boarding passengers in Tables 5 and 8 yield results that are within a second. Focusing on just the boarding passengers, parameters for the basic stop (CONST) is 4.05 seconds versus $5.14,19.12$ seconds versus 17.41 to board five passengers, and -1.45 versus -0.99 seconds for the diminishing effect of the multiple of five passengers. Similarly, the comparison of five alighting 
passengers in Tables 5 and 9 yield results that are within a second when comparing only the alighting times and the constant.

Again, the results of the simulation should be used in comparing scenarios and not be used for precise estimates of dwells.

Table 6. Bus Dwell Time Model: Boardings Only - AM Peak Period

\begin{tabular}{|lrrr|}
\hline Name & Coeff. & Std. Err. & T-Ratio \\
\hline ONS & 3.825 & 0.063 & 61.000 \\
ONS2 & -0.058 & 0.005 & -11.340 \\
FRICTION & 0.040 & 0.014 & 2.845 \\
ONTIME & -0.164 & 0.020 & -8.021 \\
LOW & -0.464 & 0.103 & -4.483 \\
CONST. & 4.054 & 0.126 & 32.230 \\
\hline N & 16,509 & & \\
ADJ. R2 & 0.3819 & & \\
\hline
\end{tabular}

Table 7. Bus Dwell Time Model: Alightings Only - PM Peak Period

\begin{tabular}{|lccc|}
\hline Name & Coeff. & Std. Err. & T-Ratio \\
\hline OFFS & 1.566 & 0.057 & 27.610 \\
OFFS2 & -0.016 & 0.006 & -2.703 \\
FRICTION & 0.119 & 0.012 & 10.150 \\
ONTIME & -0.046 & 0.008 & -5.971 \\
LOW & 0.523 & 0.079 & 6.651 \\
CONST. & 5.001 & 0.100 & 49.850 \\
\hline N & 18,098 & & \\
ADJ. R2 & 0.1616 & & \\
\hline
\end{tabular}


Table 8. Simulation of Bus Dwell Times by Number of Boardings AM Peak Period

\begin{tabular}{|lrrrrrr|}
\hline & \multicolumn{6}{c|}{ Boardings } \\
\cline { 3 - 7 } Name & Coeff. & $\mathbf{1}$ & $\mathbf{2}$ & $\mathbf{5}$ & $\mathbf{1 0}$ & $\mathbf{1 5}$ \\
\hline ONS & 3.825 & 3.82 & 7.65 & 19.12 & 38.25 & 57.37 \\
ONS2 & -0.058 & -0.06 & -0.23 & -1.45 & -5.80 & -13.04 \\
FRICTION & 0.040 & & & & & \\
ONTIME & -0.164 & -0.26 & -0.26 & -0.26 & -0.26 & -0.26 \\
LOW & -0.464 & -0.46 & -0.46 & -0.46 & -0.46 & -0.46 \\
CONST. & 4.054 & 4.05 & 4.05 & 4.05 & 4.05 & 4.05 \\
\hline TOTAL DWELL & & 7.10 & 10.75 & 21.01 & 35.79 & 47.67 \\
\hline
\end{tabular}

Table 9. Simulation of Bus Dwell Times by Number of Alightings PM Peak Period

\begin{tabular}{|lrrrrrr|}
\hline & & \multicolumn{5}{c|}{ Alightings } \\
\cline { 3 - 7 } Name & Coeff. & $\mathbf{1}$ & $\mathbf{2}$ & $\mathbf{5}$ & $\mathbf{1 0}$ & $\mathbf{1 5}$ \\
\hline ONS & 1.566 & 1.57 & 3.13 & 7.83 & 15.66 & 23.49 \\
ONS2 & -0.016 & -0.02 & -0.06 & -0.39 & -1.58 & -3.55 \\
FRICTION & 0.119 & & & & & \\
ONTIME & -0.046 & -0.21 & -0.21 & -0.21 & -0.21 & -0.21 \\
LOW & 0.523 & 0.52 & 0.52 & 0.52 & 0.52 & 0.52 \\
CONST. & 5.001 & 5.00 & 5.00 & 5.00 & 5.00 & 5.00 \\
\hline TOTAL DWELL & & 6.87 & 8.39 & 12.75 & 19.40 & 25.26 \\
\hline
\end{tabular}




\section{Discussion}

The original purpose of this research was to identify the effects of delay that occur at unexpected times, such excess dwell time resulting from bus lift operations. Our research provides an estimate of delay at the time of initiation of the occurrence, which needs to be updated with the actual time of delay at the ending time of the occurrence. This research provides a basis for shifting from predicting transit bus arrival times for customers based on normal operating conditions to one that predicts transit vehicle arrival time when operating conditions are not normal (Dueker, et al. 2001).

An ancillary benefit of this research identified the general determinants of bus dwell time. As expected, passenger activity is an important determinant. In addition, the archived AVL/APC data provided a large sample size that allowed examination of determinants, such as low floor buses, time of day, and route type effects, and allowed estimation of a separate model for dwells with lift operation only.

Automation of dwell time data collection results in a tradeoff of labor-intensive direct observation but small sample data with the large samples of more consistent data. While directly observing door-specific passenger activity, fare payment method, and unproductive door opening time, as called for in the Transit Capacity and Quality of Service Manual, improvements in automated data collection may be able to deal with these issues. For example, integration of farebox and bicycle rack with a BDS data collection system is possible in the future. This would deal with the effect of fare payment method and use of the bicycle rack on dwell time. In addition, validation of dwell time data is needed. TriMet has validated its APC data by viewing on-board video camera data. This procedure could be extended to record the time of passenger activity to the door opening time from the automated data.' This would provide evidence to determine a better cutoff value for maximum dwell time. The current value of 180 seconds is too arbitrary; it needs to be replaced with a value that includes most passenger activity and reduces the amount of unneeded door opening time. In addition, the validation procedure could include observation of fare payment method and bicycle rack use prior to integration at the hardware level. 


\section{Acknowledgements}

The authors gratefully acknowledge support provided by TriMet and the US Department of Transportation (USDOT) University Transportation Centers Program, Region X (TransNow). The contents of this paper reflect the views of the authors, who are responsible for the facts and the accuracy of the data presented herein. The contents do not necessarily reflect the views or policies of TriMet or the USDOT.

\section{Endnotes}

${ }^{1}$ Long dwells are likely to be associated with vehicle holding actions or operator shift changes, and thus should be excluded from the analysis.

${ }^{2}$ Table 5 contains coefficients of the full-sample dwell time model.

${ }^{3} \mathrm{~A}$ passenger friction factor was constructed to account for passenger activity on buses with standees. It was posited that heavily loaded buses have greater dwell times. A proxy variable was constructed by adding ONS, OFFS, and STANDEES. STANDEES are the number of passengers when LOAD minus $85 \%$ of bus capacity is positive. LOAD is an APC calculated number that keeps a running count of ONS and OFFS.

${ }^{4}$ Kraft and Deutschman (1977) did not find any difference in the average service time for each successive passenger to board.

${ }^{5}$ Operators tend to hurry to regain schedule adherence.

${ }^{6}$ The farebox is not integrated with the BDS, so we do not know the proportion of cash paying boarding passengers at the stop level.

${ }^{7}$ Kraft and Deutschman (1977) used photographic studies of passenger movements through bus doors. 
Journal of Public Transportation, Vol. 7, No. 1, 2004

\section{References}

Bertini, R. L. and A. M. El-Geneidy. 2004. Modeling transit trip time using archived bus dispatch system data. Journal of Transportation Engineering, 130 (1): 56 67.

Dueker, K. J., T. J. Kimpel, J. G. Strathman, R. L. Gerhart, K. Turner, and S. Callas. 2001. Development of a statistical algorithm for real-time prediction of transit vehicle arrival times under adverse conditions. Portland, OR: Project Report 123, Center for Urban Studies, Portland State University.

Furth, P. G., B. Hemily, T. H. Mueller, J., Strathman. Forthcoming. Uses of archived $A V L-A P C$ data to improve transit performance and management: Review and potential. TRCP Project H-28. Washington, DC: Transportation Research Board.

Guenthner, R. P. and K. Hamat. 1988. Transit dwell time under complex fare structure. Transportation Engineering Journal of ASCE, 114 (3): 367-379.

Guenthner, R. P. and K. C. Sinha. 1983. Modeling bus delays due to passenger boardings and alightings. Transportation Research Record, 915: 7-13.

Highway Capacity Manual (HCM), Special Report 209, Transportation Research Board, 1985, p. 12-3.

Kimpel, T. J. 2001. Time point level analysis for transit service reliability and passenger demand. Portland, OR: Special Report 36, Center for Urban Studies, Portland State University.

Kimpel, T., J. Strathman, S. Callas, D. Griffin and R. Gerhart. 2003. Automatic Passenger Counter Evaluation: Implications for National Transit Database Reporting. Transportation Research Record, 1835: 109-119.

Kraft W. and T. Bergen. 1974. Evaluation of passenger service times for street transit systems. Transportation Research Record, 505: 13-20.

Kraft, W. and H. Deutschman. 1977. Bus passenger service-time distribution. Transportation Research Record, 625: 37-43.

Levinson, H. S. 1983. Analyzing transit travel time performance. Transportation Research Record, 915: 1-6.

Lin T. and N. H. Wilson. 1992. Dwell time relationships for light rail systems. Transportation Research Record, 1361: 287-295. 
Strathman, J.G., T.J. Kimpel., and K.J. Dueker. 1999. Automated Bus Dispatching, Operations Control and Service Reliability. Transportation Research Record, 1666: 28-36.

Strathman, J.G., T.J. Kimpel, K.J. Dueker, R.L. Gerhart, K. Turner, G. Taylor, and D. Griffin. 2000. Service reliability impacts of computer-aided dispatching and automatic vehicle location technology: a case TriMet case study. Transportation Quarterly, 54 (3): 85-102.

Strathman, J.G., T.J. Kimpel, K.J. Dueker. 2001a. Evaluation of transit operations: Data applications of TriMet's automated bus dispatching system. Portland, OR: Project Report 120, Center for Urban Studies, Portland State University.

Strathman, J.G., T.J. Kimpel, K.J. Dueker, R.L Gerhart, K. Turner, and D. Griffin. (2001b). Bus transit operation control: review and an experiment involving TriMet's automated bus dispatching system. Journal of Public Transportation, 4 (1): $1-26$

Transit Capacity and Quality of Service Manual, First Edition. 1999. Transit Cooperative Research Program, Transportation Research Board, Web Document 6, Part 2: 290 - 2-91, available at http://gulliver.trb.org/publications/tcrp/ tcrp_webdoc_6-a.pdf . 


\section{About the Authors}

KenNeth J. Dueker (duekerk@pdx.edu) is emeritus professor of urban studies and planning, and research associate of the Center for Urban Studies at Portland State University. He formerly directed both the Center for Urban Studies and the Transportation Studies Center. His interests are in transportation and land use interactions, travel and parking behavior, and geographic information systems - transportation.

Thomas J. Kimpel (kimpelt@pdx.edu) is a research associate in the Center for Urban Studies at Portland State University. His interests are in transit operations, service reliability, passenger demand analysis, and geographic information systems.

James G. Strathman (strathmanj@pdx.edu) is a professor of urban studies and planning and director of the Center for Urban Studies at Portland State University. His research focuses on transit operations and planning and travel behavior.

Steve Callas (callasc@TriMet.org) is coordinator of service and performance analysis at TriMet in Portland Oregon, where he is responsible for the agency's performance statistics. He has a master's of urban and regional planning from the University of lowa. 